\title{
Um Empurrãozinho no Bolsa Família: uma Proposta de Uso de Ferramentas Comporta- mentais no Programa
}

\section{A Slight Nudge on Bolsa Família: a Proposal for the Use of Behavioral Tools in the Pro- gram}

\author{
Henrique Santos de Faria \\ Instituto Brasiliense de Direito Público - IDP - Brasil \\ hsdefaria@gmail.com \\ ORCID: 0000-0003-3071-7937 \\ Luís Henrique Paiva \\ Instituto Brasiliense de Direito Público - IDP - Brasil \\ lhspaiva1@gmail.com \\ ORCID: 0000-0001-9197-7332
}

Submetido em 22/01/2020; Aprovado em 21/04/2020.

\section{Resumo}

Objetivo: O Programa Bolsa Família (PBF) é uma importante política pública que possibilitou o rompimento do ciclo da miséria para milhões de famílias. Consolidado o programa, faz-se mister analisar de que maneiras é possível aprimorá-lo, a fim de aumentar o cumprimento das denominadas condicionalidades (tais quais: frequência escolar e cumprimento do calendário de vacinação). Assim, a presente pesquisa explora aspectos específicos do PBF, analisando suas principais condicionalidades sob a perspectiva da Economia Comportamental (EC) e averiguando quais medidas poderiam contribuir para o aprimoramento do Programa. Metodologia: Foi feita uma revisão bibliográfica acerca do PBF e dos principais pressupostos da EC, detalhando possíveis insights que pudessem ser utilizados no aprimoramento do Programa. Resultados: À luz da EC, o presente estudo propõe uma simplificação na linguagem utilizada com o beneficiário do programa na carta de advertência que é enviada em caso de descumprimento de alguma condicionalidade. 0 presente estudo também propõe uma avaliação de impacto, com o intuito de apurar se os insights comportamentais sugeridos produziram os efeitos esperados. Contribuições práticas: 0 presente estudo pretende contribuir para o aprimoramento do PBF enquanto política pública, para aumentar o índice de cumprimento das condicionalidades associadas ao programa. Contribuições acadêmicas: Na seara acadêmica, o presente estudo traz contribuições para a literatura de políticas sociais, explorando a otimização e a simplificação da comunicação entre os beneficiários de uma política pública e o Estado. Além disso, o artigo faz contribuições inovadoras para a literatura brasileira sobre comunicação governamental.

Palavras-chave: Bolsa Família; condicionalidades; economia comportamental.

\begin{abstract}
Objective: The Bolsa Família Program (PBF) is an important public policy that made it possible to break the cycle of misery for millions of families. Once the program is consolidated, it is necessary to analyze the ways in which it can be improved, in order to increase compliance with the so-called conditionalities (such as school attendance and compliance with vaccination schedules). Thus, this research explores specific aspects of the PBF, analyzes its main conditionalities from the perspective of Behavioral Economics (BE) and investigates which measures could contribute to the improvement of the Program. Methodology: A bibliographic review about the PBF and the main assumptions of BE was made, detailing possible insights that could be used in the improvement of the Program. Results: In light of BE, this study proposes a simplification in the language used with the beneficiaries of the program in the warning letter that is sent in case of non-compliance with any conditionality. This study also proposes an impact evaluation to ascertain whether the suggested behavioral insights produced the expected effects. Practical contributions: This study aims to contribute to the improvement of the PBF as a public policy,
\end{abstract}


to increase the rate of compliance with the conditionalities associated with the program. Academic contributions: In the academic field, this study contributes to the social policy literature, exploring the optimization and simplification of communication between the beneficiaries of public policy and the State. In addition, the article makes innovative contributions to the Brazilian literature on government communication.

Keywords: Bolsa Família; conditionalities; Behavioral Economics.

\section{Introdução}

Os programas sociais de transferência de renda com condicionalidades representam um grande avanço na concepção e na implementação das políticas sociais no Brasil. Através do amadurecimento e fortalecimento do Programa Bolsa Família (PBF), o Estado brasileiro conseguiu implementar políticas de transferência de renda com condicionalidades de educação e saúde, que estenderam a proteção social a famílias em situação de vulnerabilidade e permitiram reduzir a pobreza no curto prazo, melhorando, ao fim, a formação de capital humano. Essas condicionalidades, inseridas dentro de uma política pública, trouxeram diversos benefícios para o sucesso do PBF, gerando suas consequências diretas quais sejam: a melhora dos indicadores de educação e saúde das famílias beneficiárias e o aprimoramento da oferta de serviços públicos essenciais, por parte do poder público local (Paiva, Falcão \& Bartholo, 2013).

Apesar dos avanços trazidos pelo PBF, contudo, um número considerável de famílias brasileiras descumpre essas condicionalidades impostas pelo governo federal como contrapartida ao auxílio financeiro do PBF, o que faz com que seus benefícios sejam bloqueados, suspensos ou mesmo cancelados. Nos últimos anos, por exemplo, o PBF protagonizou notícias destacando o desligamento de milhares de famílias (ver, por exemplo, o caso do Maranhão: <https:/glo.bo/2KjS1LX>), e a maior parte delas desconhecia os motivos que culminaram nesses resultados. 0 próprio Ministério da Cidadania apurou que mais de 170 mil beneficiários foram atingidos com bloqueios, suspensões ou cancelamentos, em 2019, em razão do não cumprimento das condicionalidades do PBF (https://bit.ly/2RV0cCA. Os dados têm setembro como mês de referência).

0 governo federal, por sua vez, argumenta que boa parte dos cancelamentos de benefícios decorre da inconsistência de informações cadastrais dos beneficiários, o que pode ser indício de fraudes no programa (https://g1.globo.com/to/tocantins/noticia/2020/03/02/mais-de-20-mil-pessoas-perdem-beneficio-do-bolsa-familia-em-um-ano-no-tocantins.ghtml). Entretanto, é possível que parte dessa estatística esteja relacionada à simples falha de comunicação entre o governo federal e os beneficiários do programa, os quais podem não estar suficientemente informados acerca das condicionalidades do PBF e de sua situação em relação a elas. Os indivíduos - tanto os beneficiários quanto os servidores governamentais responsáveis pela comunicação - são agentes comportamentais, que possuem atenção, racionalidade e autocontrole limitados; utilizam heurísticas e regras de bolso para realizar operações que, de outra forma, exigiriam cálculos complexos; e são afetados por normas sociais e modelos mentais (Banco Mundial, 2015).

Por esse motivo, e considerando que o cumprimento das condicionalidades é fundamental para o sucesso do PBF, acredita-se que essa política pública poderia se beneficiar de novas estratégias para aprimorar a comunicação com a população, valendo-se de estratégias que possam detalhar, de forma clara e precisa, quais condicionalidades precisam ser cumpridas e quais as consequências que a situação de descumprimento pode provar. Esse é o objetivo do presente estudo: sugerir uma forma de intervenção, à luz dos ensinamentos da Economia Comportamental (EC) - definida por Samson (2015) como "o estudo das influências cognitivas, sociais e emocionais observadas sobre o comportamento econômico das pessoas" (Samson, 2015, p. 26) -, que poderá influenciar o beneficiário no cumprimento das condicionalidades do PBF, evitando a suspensão ou cancelamento de seu benefício.

0 uso da EC pelos governos não é recente. Ela já foi incorporada em diversos setores da administração pública, objetivando trazer novas percepções sobre como os indivíduos reais agem de fato - e não como deveriam agir (por exemplo, o amplo levantamento de experiências internacionais reunido por OCDE, 2017). Parte relevante das intervenções comportamentais na área de políticas públicas ocorre na forma como o Estado se comunica com seus beneficiários, seus regulados e, eventualmente, seus próprios membros. Trata-se, portanto, de uma abordagem que traz novas contribuições para uma área (a comunicação de governo) de estudo em políticas públicas já bem estabelecida. 
Como destacado por Cezar (2018), sobre a importância da comunicação entre o governo e a sociedade para que sejam implementadas políticas públicas:

"A comunicação atua então nas políticas públicas como um meio necessário para a divulgação das etapas e a mobilização dos envolvidos. Seu objetivo principal é a diminuição das barreiras entre governantes e governados, no intuito de disseminar as informações contidas e preconizadas em lei (Saldanha, 2006). 0 objetivo ao repassar tais informações centra-se na importância de cumprir as metas estipuladas e buscar solucionar determinada situação, vivenciada no âmbito do espaço público." (Cezar, 2018, p. 53)

Ocorre que, no Brasil, poucos trabalhos se debruçaram sobre a comunicação governamental com os beneficiários de programas sociais e políticas públicas. Dessa forma, este artigo propõe, com base em insights retirados da EC, verificar quais ferramentas poderiam ser utilizadas pelo governo federal para aprimorar os mecanismos de comunicação dos entes federados com os beneficiários de um dos mais bem sucedidos programas sociais do país. Para tanto, pretende-se propor uma nova forma de comunicação entre o governo federal e o cidadão beneficiário do PBF, qual seja, a carta de advertência enviada no caso de descumprimento das condicionalidades, a fim de que ela seja elaborada através de uma linguagem simplificada e com ferramentas que induzem uma tomada de decisão que favoreça a política do Programa Bolsa Família.

\section{0 Programa Bolsa Família}

O Programa Bolsa Família (PBF) é um Programa de Transferência Condicionada de Renda (PTCR), concebido, inicialmente, como parte integrante de uma rede de proteção social, cujo objetivo era combater as causas estruturais da pobreza, bem como interromper o ciclo intergeracional de transmissão da pobreza entre as famílias (Agatte \& Antunes, 2014, p. 37). De fato, desde a sua criação, o PBF assumiu o protagonismo no que se refere à diminuição sistemática da quantidade de famílias em situação de pobreza extrema no País (Cambraia, 2012), efeito esse que se mostra ainda mais importante quando se considera o baixo custo relativo do programa, inferior a 0,5\% do PIB brasileiro.

O PBF também teve um longo processo de amadurecimento para se tornar o que é hoje, superando diversas críticas. Muitos acreditavam que o programa poderia criar algum tipo de dependência negativa - situação na qual "necessidades atuais são satisfeitas ao custo de reduzir a capacidade dos beneficiários de satisfazer suas necessidades básicas no futuro sem assistência externa" (Lentz, Barrett \& Hoddinott, 2005, p. 10). Avaliações do impacto do programa na oferta de trabalho, entretanto, afastaram essa hipótese. Também surgiram críticas no sentido de que o programa poderia levar a um aumento na fecundidade das beneficiárias, o que, novamente, se provou falso (Simões \& Soares, 2012).

Ao longo dos anos de vigência do Programa Bolsa Família (PBF), o programa passou a apresentar resultados positivos em indicadores de educação e saúde (Cotta \& Paiva, 2010). Mais do que isso, passou a ser considerado uma ótima ferramenta para o combate à pobreza (Soares \& Sátyro, 2009). Januzzi e Pinto (2010) destacam vários indicadores e resultados de pesquisas empíricas ligando o PBF a uma significativa melhoria no bem-estar do cidadão. Destacam-se a desmistificação de que o PBF causaria um suposto "efeito preguiça" e um suposto efeito pró-natalista do programa. 0 monitoramento do cumprimento das condicionalidades do programa está potencialmente ligado a esse sucesso.

O PBF decorreu de uma iniciativa de unificação de vários programas de transferência de renda (todos os programas unificados foram elencados no $\S^{\circ}{ }^{\circ}$ do art. $3^{\circ}$ da Lei 10.386/2004.) que existiam até então, todos independentes entre si, oriundos de dispositivos legais distintos e coordenados por Ministérios diferentes. Essa unificação buscou eliminar a baixa escala desses programas, além da possibilidade de sobreposição de benefícios decorrentes das múltiplas iniciativas (Cotta \& Paiva, 2010, p. 1), concentrando todos os esforços em um único programa para alavancar o acesso dos beneficiários.

Além da iniciativa de unificação, o sucesso do programa também é resultado de um grande esforço interfederativo (Lindert et al, 2007; Maurício \& Cardoso, 2019), por pressupor uma forte colaboração entre o governo federal, estados e municípios. Dois fatores se destacam nessa cooperação interfederativa. 0 primeiro é o termo de adesão assinado por todos os municípios brasileiros com o Ministério da Cidadania. Neste termo, foram formalizados os compromissos dos participantes do programa, no qual se destaca o compromisso dos municípios de nomearem um gestor do programa e instituírem uma Instância de Controle Social, que é responsável por realizar o acompanhamento da gestão do Cadastro e do PBF (Paiva, Falcão \& Bartholo, 2013).

O segundo fator foi a criação do Índice de Gestão Descentralizada (IGD). Esse índice é composto 
por indicadores de qualidade dos registros no Cadastro Único (plataforma que unificou todos os programas de transferência de renda) e indicadores de acompanhamento das condicionalidades. A sua função é mensurar a qualidade da gestão do PBF e, por meio desse índice, ajustar o valor dos recursos de gestão que será repassado aos municípios e estados (Paiva, Falcão \& Bartholo, 2013).

$\mathrm{O}$ PBF tem sua atuação pautada em três vértices: transferência direta de renda; ruptura do ciclo de pobreza intergeracional por meio do acompanhamento das condicionalidades; e instituição de programas complementares que visem à melhora dos serviços públicos prestados a essas famílias (Agatte \& Antunes, 2014). Sendo um dos principais vértices que orientam o programa, as condicionalidades se justificam por possuírem uma importância fundamental: são elas que demonstram com clareza a intenção política do programa de transferência de renda (por exemplo, estimular a frequência escolar ou o acesso aos programas de saúde) e que acabam por conferir um alto grau de legitimidade da política pública perante a sociedade como um todo e, também, perante as famílias atendidas (Lindert, Linder, Hobbsa \& Briére, 2007; Zucco, Luna \& Baykal, 2020).

\subsection{As condicionalidades no PBF}

Um programa de transferência de renda com condicionalidades, como o PBF, reflete uma intenção por parte do governo federal de garantir direitos fundamentais expressos na Constituição, como o acesso à saúde, à educação e à assistência social. Nesse sentido, as condicionalidades possuem um papel fundamental, já que fazem com que as famílias beneficiárias sejam induzidas a acessar esses serviços públicos. Sabe-se, além disso, que crianças mais saudáveis e educadas terão uma probabilidade maior que a dos seus pais de escapar da pobreza (Lindert, Linder, Hobbsa \& Briére, 2007), o que faz do PBF uma política pública focada no empoderamento futuro das famílias.

Por sua vez, o não cumprimento dessas condicionalidades também tem uma função pública para o governo nos termos do monitoramento da implementação da política, podendo servir de alerta para que as autoridades intervenham, de maneira específica, naquela família ou região. Operacionalmente, o não cumprimento de alguma condição por parte de uma família beneficiária serve como alerta para o governo federal no sentido de que essa família pode estar em situação de risco e precisando de um cuidado extra. A premissa é de que, como o programa é voltado para a população em estado de pobreza e extrema pobreza, pode haver algum fator que esteja impedindo o acesso por parte dessa família aos serviços de saúde e educação e que seja revelador de alguma vulnerabilidade. Assim, o não cumprimento de condicionalidades exige um acompanhamento constante por parte das autoridades (Lindert, Linder, Hobbsa \& Briére, 2007; Ximenes e Agatte, 2011).

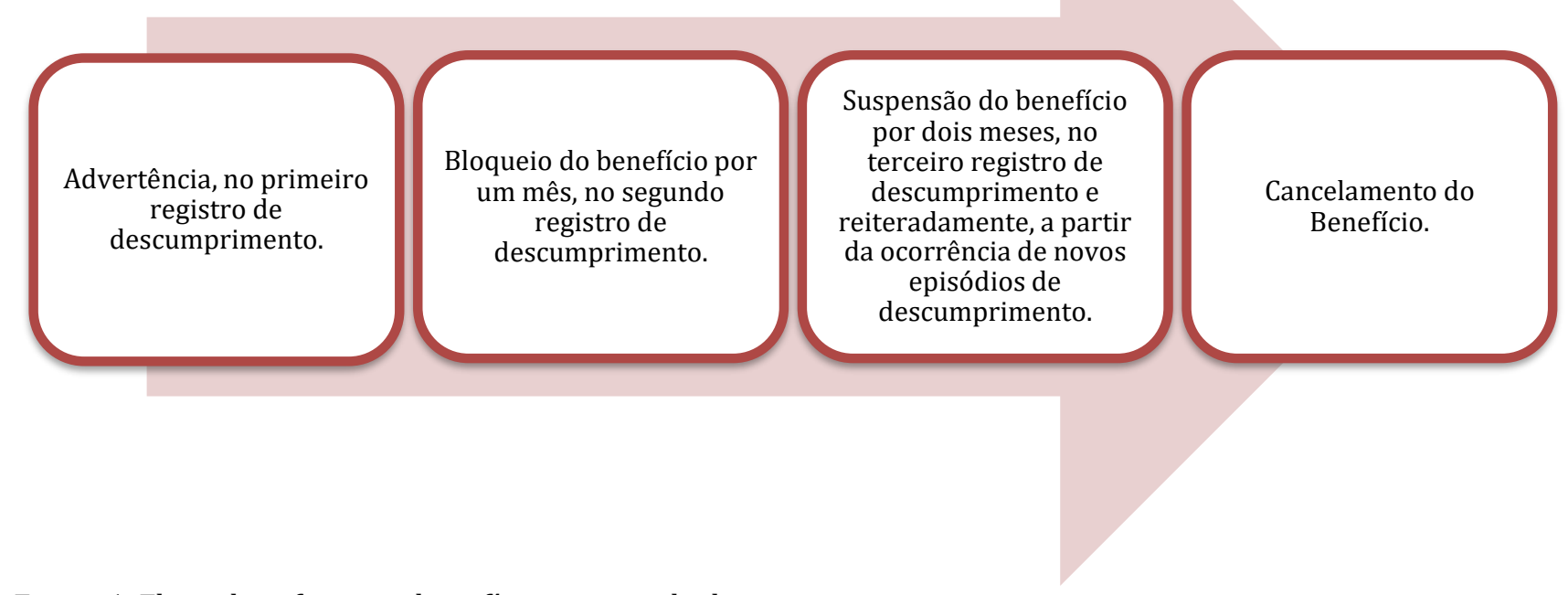

Figura 1. Fluxo dos efeitos no benefício em caso de descumprimento.

Fonte: Elaborada pelos autores, baseada na Portaria no 251 de dezembro de 2012 (Brasil, 2012). 
De acordo com a Portaria no 251 de dezembro de 2012 (Brasil, 2012), os efeitos para não cumprimento das condicionalidades são gradativos e aplicados de forma sucessiva, iniciando-se com uma advertência e podendo resultar no cancelamento definitivo do PBF. Na figura 1, são expostos os efeitos do descumprimento por parte das famílias.

Nesse processo, é importante destacar algumas especificidades. A advertência não gera nenhuma repercussão financeira no benefício, funcionando como um mero alerta. No caso de bloqueio, o benefício fica retido por um mês e poderá ser sacado a posteriori, quando a família voltar a cumprir as condicionalidades. Já na suspensão, a família fica definitivamente sem a verba relativa ao período de dois meses, podendo voltar a receber, caso saia da situação de descumprimento. Finalmente, o cancelamento segue regras próprias e só pode ser feito caso a família esteja: (i) em fase de suspensão; (ii) com acompanhamento familiar registrado no Sistema de Condicionalidades - Sicon- por um ano; e (iii) descumprindo novamente alguma condicionalidade.

A partir desses fatos, fica evidente a importância da advertência enviada ao beneficiário através de uma carta, pois ela se trata de uma comunicação fundamental relacionada a uma condição que poderá culminar na suspensão do benefício. Nessa fase de advertência, o beneficiário ainda recebe os valores do Programa e possui uma chance maior de voltar a uma situação de regularidade, o que reforça a importância desse momento para que o beneficiário não seja prejudicado - o que, é importante mencionar, não é o verdadeiro propósito da política. A questão que se coloca é se é possível melhorar essa comunicação com os beneficiários em situação de descumprimento. Januzzi e Pinto (2010) acreditam que existe espaço para aprimoramentos dentro PBF e que a busca por inovações que, uma vez testadas, possam gerar um efeito ainda melhor do Programa.

Como já mencionado, a implementação da EC por parte dos governos não é recente, e a comunicação é uma das áreas mais prestigiadas nesse aspecto, justamente porque diz respeito à parte de comunicação com o beneficiário das políticas públicas. Algumas das intervenções comportamentais tornaram-se muito conhecidas por se basearem em alterações relativamente pequenas na comunicação com os beneficiários, de custos muito baixos e benefícios surpreendentemente altos. Talvez o maior exemplo seja a intervenção conduzida pelo Behavioural Insights Team (BIT), junto ao Her Majesty Revenue and Customs (o equivalente da Receita Federal, no Reino Unido). Por meio de alterações sutis nas cartas enviadas a contribuintes em débito, a intervenção aumentou o percentual de pagamento de $67,5 \%$ para até $83,0 \%$ na tentativa mais bem-sucedida (que fazia referência a normas sociais seguidas pelos moradores da cidade em que vivia o contribuinte) (BIT, 2012). Também por meio de alterações sutis em mensagens de texto, o BIT conseguiu aumentar o comparecimento a feiras de emprego em 16 pontos percentuais, sempre baseados em insights comportamentais (Briscese \& Tan, 2018).

Sabendo, portanto, que (i) o problema de descumprimento de condicionalidades pode estar associado a problemas de comunicação com os beneficiários, e que (ii) existem experiências demonstrando o sucesso das intervenções comportamentais nesse tipo de comunicação, serão apresentados alguns insights comportamentais, documentados por estudos empíricos da EC, os quais servirão de base para a proposta de intervenção no PBF justamente para aprimorar essa fase de comunicação durante a advertência. Sabendo que o beneficiário tem maiores dificuldades de cumprir as condicionalidades se o benefício for suspenso, é importante que a advertência seja o mais eficaz possível, o que pode ocorrer com o aprimoramento da comunicação entre os beneficiários e o governo federal por meio de intervenções pontuais.

\subsection{Aversão à perda}

O descumprimento das condicionalidades do PBF implica a possibilidade de bloqueio, suspensão ou mesmo cancelamento do benefício mensal. Como visto na seção anterior, a primeira comunicação feita com o beneficiário em situação de descumprimento é a advertência, e, justamente nesse momento - no qual o beneficiário ainda continua recebendo o benefício e possui maiores chances de voltar à regularidade - é que se deve intervir.

A primeira proposta seria, portanto, inserir nessa comunicação primeva um dispositivo denominado aversão à perda, que vem sendo destacado pela literatura empírica como um importante mecanismo comportamental para reforçar o temor de perder algo em uma tomada de decisão (Kahneman, 2012; Camerer 2000; Dellavigna, 2009).

A aversão à perda é considerada por Kahneman (2012) uma das características relacionadas ao 
comportamento humano diante de decisões econômicas. A tese, em si, é simples: o desprazer gerado por uma perda é maior que o prazer gerado por um ganho da mesma magnitude. Em outras palavras, mensurou-se experimentalmente que "as perdas assomam como maiores do que os ganhos" (Kahneman, 2012, p. 351). Há, dessa forma, uma aversão à perda. Os indivíduos preferem não sofrer a dor da perda a experimentar o prazer de um ganho da mesma escala.

Essa foi a conclusão de Kahneman e Tversky no artigo "Prospect Theory: An Analysis of Decision under Risk" de 1979. Na figura 2, Kahneman e Tversky ilustram o valor de perdas e ganhos sob o prisma da teoria da perspectiva. Percebe-se uma assimetria na função em relação ao eixo vertical, que representa o valor psicológico. Segundo Kahneman, "no ponto de referência: a reação às perdas é mais forte do que a reação aos ganhos correspondentes" (Kahneman, 2012, p.352).

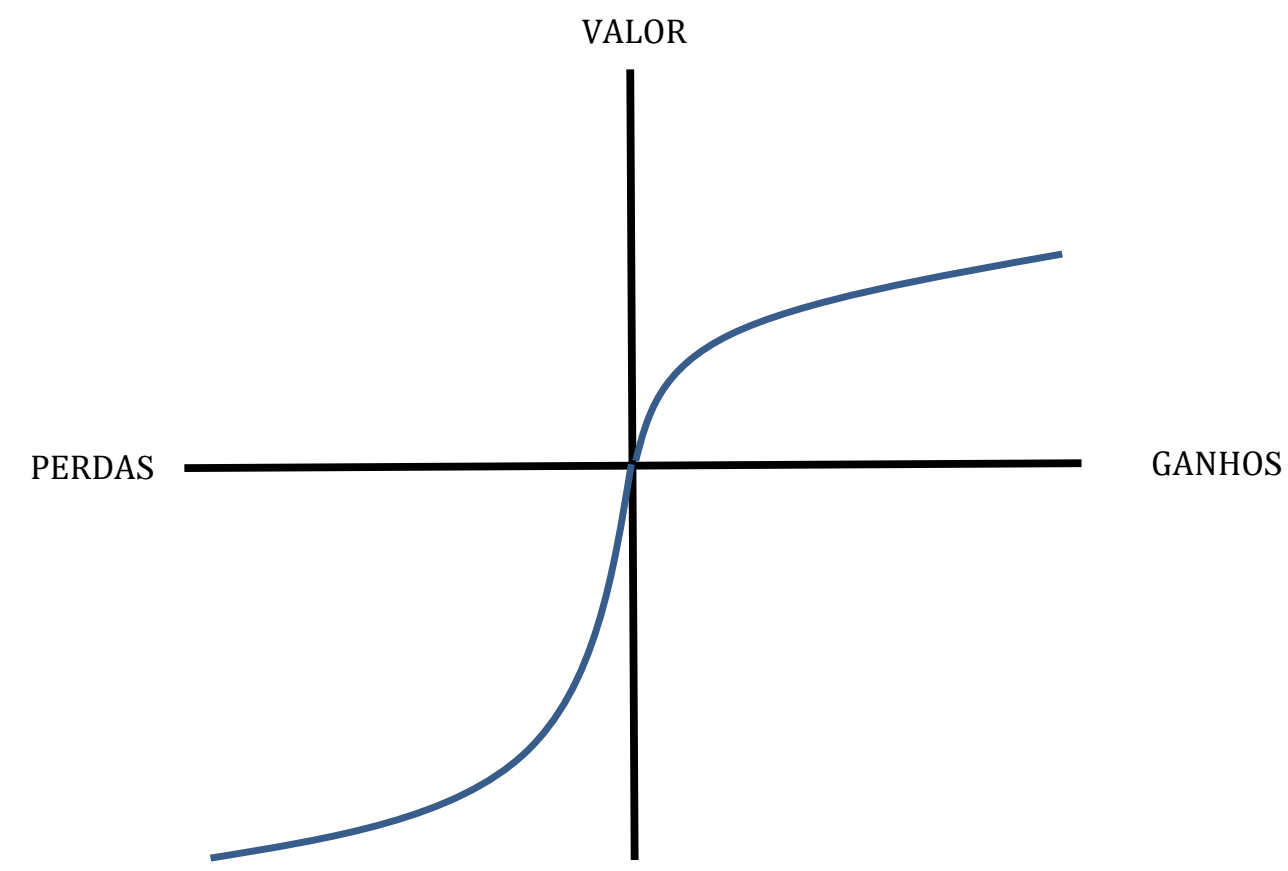

Figura 2. A função do valor na teoria dos prospectos.

Fonte: Adaptado de Kahneman e Tversky (1979).

0 conceito de aversão à perda será utilizado, neste trabalho, na proposta de reformulação das cartas que são enviadas para os beneficiários do PBF que estão em situação de descumprimento de condicionalidades. Em seu atual modelo, a carta de advertência enviada aos beneficiários não ressalta as perdas financeiras decorrentes do descumprimento das condicionalidades. De acordo com Gächter, Orzen, Renner e Starmer (2009), frames de penalidades são mais eficientes do que frames de motivação para o sucesso de uma estratégia de implementação de mudança de comportamento (apud Samson, 2015, p.363). Nesse sentido, acredita-se que o enfoque da comunicação sobre as perdas financeiras poderia estimular os beneficiários a buscarem o cumprimento das condicionalidades exigidas pelo PBF.

\subsection{Framing}

Um segundo dispositivo a ser levado em consideração para aprimorar a comunicação com o usuário seria o framing (enquadramento), que diz respeito à forma como as escolhas são apresentadas a uma pessoa e frequentemente está associado à aversão a perdas. Segundo Samson (2015), "as escolhas podem ser apresentadas de um modo que saliente aspectos positivos ou negativos da mesma decisão, levando a mudanças em sua atratividade relativa" (Samson, 2015, p. 376).

Starmer (2015) classifica, nesse sentido, o efeito framing como resultado de uma anomalia comportamental, já que produz grandes mudanças no processo decisório, mesmo não passando de pequenas alterações em como o ambiente em que se dá a escolha está estruturado. Kahneman (2012), por meio de experimentos, confirma o efeito framing no processo decisório, concluindo, a partir de duas situações equivalentes do ponto de vista lógico, que o uso de enquadramentos distintos influencia na opinião das 
pessoas.

Assim, o conceito do efeito framing é extremamente útil para o desenvolvimento de uma estratégia de comunicação eficaz, principalmente em políticas públicas, como o PBF. Neste trabalho, será usado como uma forma de encorajar os beneficiários a regularizarem suas situações de descumprimento de condicionalidades, por exemplo. Ou seja, o framing da comunicação com os beneficiários do Bolsa Família na proposta, aqui, elaborada enfatizará as perdas advindas do descumprimento das condicionalidades.

\subsection{Saliência}

Todos os dias, as pessoas são bombardeadas com uma quantidade enorme de informações. A maioria dessas informações não causa nenhum efeito no comportamento delas. As únicas que geram efeito são as que são notadas. Nesse sentido, um passo importante para governos é dar destaque às informações que podem causar algum tipo de impacto positivo no comportamento das pessoas (Sunstein, 2014).

0 conceito de saliência está ligado à atenção limitada dos agentes comportamentais e a como é importante dar destaque a determinadas informações. Para Meneguin e Ávila (2015), as informações que estão salientes e expostas de forma clara e de simples compreensão chamam mais a atenção das pessoas. Desta feita, destacar determinadas informações facilita o registro mental.

Sunstein (2014) sugere que os governos devem estar atentos ao que as pessoas não estão dando a devida atenção. Kahneman (2012) afirma que as pessoas podem ser cegas para coisas óbvias e, inclusive, para a própria cegueira. Nesse sentido, Sunstein (2014) entende que governos têm o desafio de deixar salientes as informações que realmente importam. Além disso, entende que muitos esforços de informar a população falham pelo motivo de falta de saliência.

Na proposta de intervenção, aqui, elaborada, as perdas financeiras do descumprimento das condicionalidades serão salientadas na comunicação com os beneficiários do PBF.

\section{Casos de aplicação de insights comportamentais em políticas públicas}

Como destacado anteriormente, a EC é o estudo de diversas influências sobre o comportamento econômico dos indivíduos (Samson, 2015). Vários governos pelo mundo vêm considerando insights comportamentais na construção de suas políticas públicas. Nesse sentido, a OCDE lançou, no ano de 2017, um relatório intitulado Behavioural Insights and Public Policy - lessons from around the world, no qual são relatados casos de aplicação de conhecimentos relativos à Economia Comportamental. A intenção foi divulgar as experiências para que mais países passem a adotar essas práticas em suas políticas públicas. Para o presente estudo, serão apresentados dois casos nos quais foram utilizados insights comportamentais similares aos que serão utilizados nas propostas que serão apresentadas para o PBF. 0 caso chileno é o primeiro que merece destaque.

No ano de 2015, o governo chileno, motivado por mais de 30.000 reclamações acerca das contas de luz, optou por melhorar o layout desses boletos. Observou-se que, muitas vezes, a linguagem utilizada era demasiadamente técnica e, por esse motivo, optou-se por uma intervenção que simplificasse essa comunicação (OCDE, 2017).

Para tanto, o governo fez uma atuação conjunta com diversos órgãos da administração pública e atuou em três estágios, por meio de três órgãos: SENARC (Servicio Nacional del Consumidor), SEC (Superintendencia de Electricidad y Combustibles) e LabGob (Laboratorio de Gobierno). 0 primeiro estágio foi conduzido pela SENARC e consistiu, basicamente, em fazer, por meio de pesquisas, o diagnóstico correto dos problemas das contas de luz e quais das suas partes chamavam mais atenção dos consumidores. 0 segundo estágio, conduzido pelo LabGob, se resume à criação e testes de protótipos.

Todos esses protótipos possuíam seis características que os distinguiam dos modelos anteriores, quais sejam: (i) uso de linguagem simples, informando as definições dos termos utilizados na conta; (ii) apresentação das informações de forma hierárquica de relevância, dando mais importância ao valor a ser pago e a data de vencimento; (iii) explicitação das informações acerca dos valores das diferentes faixas de consumo; (iv) informações detalhadas e personalizadas do consumo de cada um; (v) informações claras acerca das autoridades governamentais responsáveis pelo serviço de energia elétrica; e (vi) informações acerca da economia de energia elétrica. 0 terceiro e último estágio, por fim, foi o lançamento do piloto, elaborado com base no protótipo criado. Começou-se a implementação em três municípios, tendo sido apurado que os protótipos que obtiveram maiores índices foram: a confiança na conta 
(47,2\%), clareza da conta (50,6\%), entendimento da conta $(49,3 \%)$ e satisfação com a conta $(47,3 \%)$, quando comparados com os modelos anteriores (OCDE, 2017).

O segundo caso ocorreu no ano de 2015, na cidade de Filadélfia (Pensilvânia, Estados Unidos da América) e tinha por objetivo aumentar a participação dos seus cidadãos da terceira idade em um programa social da prefeitura (OCDE, 2017).

Com o intuito de aliviar o peso das contas sobre as pessoas que perderam a força de trabalho que uma vez tiveram, a prefeitura oferece aos seus cidadãos da terceira idade um desconto de $25 \%$ nas respectivas contas de luz. Apesar disso, a taxa de adesão ao programa era relativamente baixa. Nesse sentido, foram desenhadas intervenções que objetivavam motivar os cidadãos a reivindicarem o referido desconto (OCDE, 2017).

Para tanto, foram selecionados 6 mil cidadãos da terceira idade, que já participavam de outros programas de descontos voltados para essa faixa etária, para que fossem testadas várias combinações de mensagens e sequências de divulgação, mensurando-se os possíveis impactos. A divulgação consistia no envio de cartas em diversos modelos e em ligações para as residências dessas pessoas. Em todas essas comunicações, os cidadãos eram encorajados a participar do programa, sempre explorando, nas mensagens, os vieses de aversão à perda e normas sociais (OCDE, 2017).

Os resultados indicaram que as cartas enviadas em envelopes maiores se mostraram mais efetivas que os outros métodos utilizados. No entanto, esse método se mostrou pouco escalável devido ao alto custo agregado. Apesar disso, a prefeitura tirou lições de aprendizado desse experimento e passou a considerar o custo agregado dessa comunicação ao testar um próximo modelo em futuros estudos. Em um teste subsequente, o envelope grande foi substituído por um envelope em tamanho normal, mas com uma coloração que os distinguia dos demais, com o intuito de os destacar, sem incorrer em um custo de postagem mais alto (OCDE, 2017).

A proposta de intervenção que será feita nesse artigo levou em consideração casos como os descritos acima.

\section{Proposta: um novo modelo de advertência para beneficiários em situação de descumprimento de condicionalidades do Bolsa Família}

A partir das propostas estudadas, dos conceitos abordados e tendo como premissa que a política pública do Bolsa Família, tão bem-sucedida, pode ser aprimorada, esta seção tem por objetivo apresentar uma proposta de intervenção no PBF, elaborada pelos autores, com base em fundamentos e teorias da EC.

A intervenção é uma proposta de um novo modelo para as cartas de advertência que são enviadas para famílias em situação de descumprimento de alguma condicionalidade do PBF, visando a efetivar uma melhor forma de comunicação com o usuário para que ele possa regularizar sua situação o quanto antes, não perdendo o benefício concedido.

Para concluir, também será apresentada uma proposta de avaliação de impacto para essa intervenção. Ao propor uma mudança no PBF e, simultaneamente, propor a respectiva avaliação de impacto, este trabalho se alinha com uma tendência global de mudança no enfoque, que passou dos inputs para os resultados (Gertler et al., 2015).

Conforme já apresentado, uma família possui uma série de compromissos com o PBF e o recebimento do benefício está vinculado ao cumprimento dessas condicionalidades. Ao se descumprir alguma dessas condicionalidades, a família é, primeiramente, advertida sem repercussão financeira, por meio de carta e de um extrato bancário emitido pela Caixa Econômica Federal. Passada a fase de advertência, entra-se no estágio de bloqueio, suspensão e, finalmente, o cancelamento do benefício, sempre de forma gradual quando da não adequação à condicionalidade.

Dada a restrição do número e do tipo de caracteres que podem ser utilizados no extrato emitido pela Caixa, a proposta se debruçará sobre as cartas de advertência que são enviadas para famílias em situação de descumprimento de condicionalidades, objetivando promover uma melhor comunicação entre o governo e o beneficiário.

Essa proposta procura incorporar insights sobre como as pessoas reagem em situação de escassez (Mullainathan \& Shafir, 2016; Campos Filho \& Paiva, 2017). Pessoas em situação de pobreza têm o seu processo decisório prejudicado: a escassez consume "largura de banda" (bandwidth) e, com ela, capaci- 
dade cognitiva e autocontrole. Segundo os autores, em situação de escassez, cada pequena decisão demanda uma análise de custo/benefício, o que esgota a capacidade de processamento de informações, que é limitada. Situações de escassez geram um contexto no qual más decisões acabam sendo comuns, realimentando a escassez.

Veja-se que a primeira carta enviada ao beneficiário é de extrema importância e deve ser a mais clara possível, uma vez que, nesse estágio de comunicação, não há repercussão financeira no benefício dessa família, o que torna mais simples o seu retorno a uma situação regular (cf. figura 3).

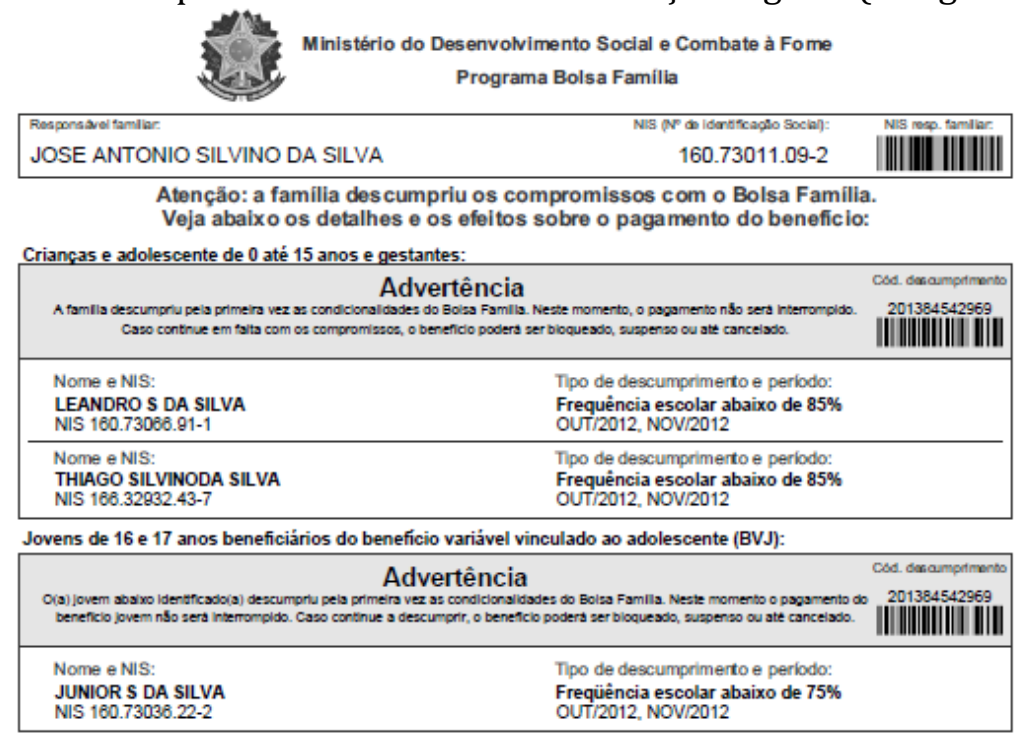
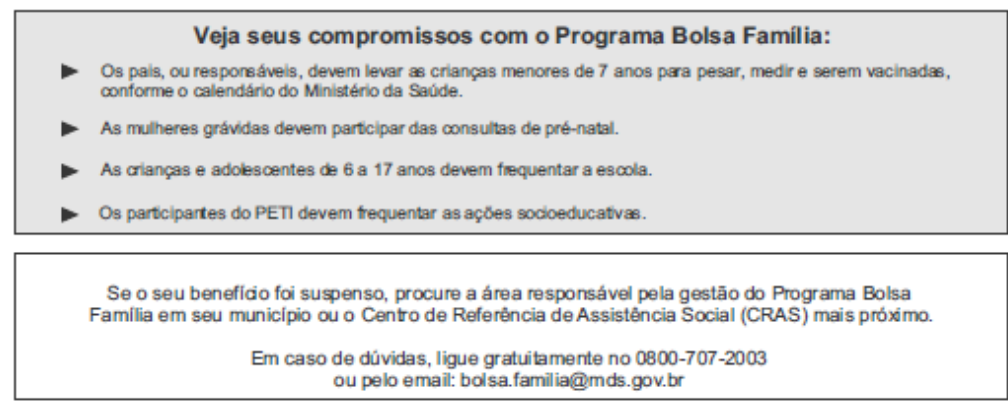

Figura 3. Primeiro modelo de carta de advertência utilizado pelo Ministério da Cidadania.

Fonte: MDS (2018)

O Ministério da Cidadania (antigo Ministério do Desenvolvimento Social - MDS), inclusive, é ciente da importância dessa primeira carta e já alterou, em ocasiões anteriores, a forma de alertar as famílias em situação de descumprimento. 0 primeiro modelo utilizado era repleto de linguagem demasiadamente técnica e de difícil entendimento por parte do público alvo do PBF. Ele foi aprimorado e culminou em um segundo modelo que já faz uso de uma linguagem mais simples e deixa as informações mais importantes de forma saliente, como se percebem nas figuras abaixo: 


\section{AVISO IMPORTANTE PROGRAMA BOLSA FAMÍLIA}

Prezado(a) [nome do beneficiário]

NIS: $[X X X . X X X . X X X-X X]$

Você está recebendo esta mensagem porque alguém de sua familia nâo cumpriu os compromissos do Bolsa familia de educaçăo ou saúde, Veja abaixo quem esteve nessa situaçồo irregular e quando isso aconteceu:

\begin{tabular}{|c|c|}
\hline Nome & Nis \\
\hline Hoao Carles A. Souzol & [123.455.789.01] \\
\hline Hobo A. Sovza] & {$[123.455 .780 .01]$} \\
\hline Hoana Carla A. Soural & {$[123.455 .789 .01]$} \\
\hline Hobe Carles A, Soura] & [123.455.769.01] \\
\hline Doos Carles A. Souzol & {$[123.455 .789 .01]$} \\
\hline [joos Carlos A, Souro] & {$[123.455 .789 .01]$} \\
\hline Hoae Carlos A. Soura] & {$[123.455 .789 .01]$} \\
\hline Hoos Crarles A. Souzol & [123.455.789.01] \\
\hline Hooo Carlos A. Souzol & [123.455.789-01] \\
\hline Jooe Corlos A. Souzol & [123.455.789-01] \\
\hline
\end{tabular}

\begin{tabular}{|c|}
\hline Situophe \\
\hline [Falou a mosola mais que a permikido] \\
\hline 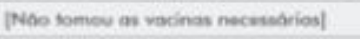 \\
\hline 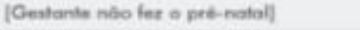 \\
\hline [Follov a encola mair que o permitido] \\
\hline [Fallov a encolo mai que a permilido] \\
\hline [Falhou a escola main que a permikido] \\
\hline [Fallow a encola mais que a permitidof \\
\hline [fablow a eacolo mais que o permikido] \\
\hline Follow a escola mais que e permikidof \\
\hline Folitou a escola mais que o per \\
\hline
\end{tabular}

Pariodo

[uUtho/2015]

[lo semestre/2015]

[lo smmentre/2015]

[uLHO/2015]

एUนHO/2015]

[ULHO/2015]

[uLtho/2015]

DULHO/2015]

HULHO/2015

juLHo/2019|

Para regularizar a situaçáo, sua familia precisa voltar a cumprir todos os compromissos do Programa Bolsa Familia.

Se sua familia está com alguma dificuldade para cumprir esses compromissos, ou se vocè acha que houve um erro, procure o setor do Bolsa Familia ou o CRAS na sua cidade.

Ficou alguma dúvida? Ligue 0800707 2003. A ligaçăo é de graça.

Lembre-se dos seus compromissos com o Programa Bolsa Familia

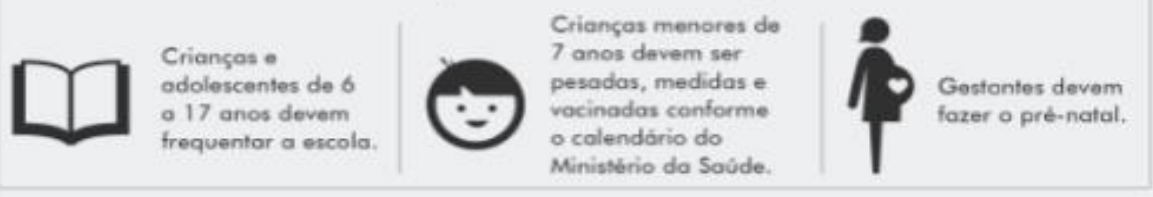

Ao gestor do Programa Bolsa Familia:

Motivo da correspondência: Descumprimento de condicionalidader

Caso a familia informe erro no registro de descumprimento ou apresente umo justificativa, cadastre e avalie o recurso no Sistema de Condicionalidodes (Sicon).

Se a familia apresentar indicios do vulnerabilidode ou risco social, comunique o setor de assistância social do seu municipio para avaliaģáo da necessidodo de acompanhamento familiar com registro no Sicon.

Figura 4. 0 atual modelo de carta de advertência enviada pelo Ministério da Cidadania. Fonte: MDS (2018)

O novo modelo foi proposto com base na carta que é atualmente utilizada pelo Ministério da Cidadania (cf. figura 5). As alterações sugeridas são reflexos de conceitos da EC para facilitar a comunicação e tentar aprimorar o alcance do objetivo, que é fazer o beneficiário irregular adequar-se o quanto antes às condicionalidades.

Na carta, portanto, foi adicionado o valor em pecúnia que a família estaria perdendo no caso de permanência em situação de descumprimento, além de ter sido sugerida uma mudança na cor do papel utilizado, optando-se pela coloração amarela quando da primeira comunicação (ainda sem corte de benefício), em alusão à cor de atenção utilizada nos semáforos de trânsito. Essa primeira mudança foi inspirada no insight de aversão à perda, enquanto a mudança na coloração do papel foi inspirada em uma intervenção realizada na cidade de Filadélfia, EUA, que optou por mudar a cor dos envelopes das cartas a fim de tentar chamar mais a atenção dos cidadãos e aumentar a adesão a um programa social local (OCDE, 2017). 


\section{AVISO IMPORTANTE PROGRAMA BOLSA FAMÍLIA}

Prezado(a) [nome do beneficiário]

NIS: $[X X X . X X X . X X X-X X]$

Atençāol Sua famflia pode PERDER IVALOR DO BENEFICOO] porque alguém sob sua responsabilidade nāo cumpriu os compromissos do Bolsa Família. Veja quem esteve nessa situaçāo irregular e qual o valor que a sua família pode perder.

\begin{tabular}{|c|c|c|c|c|}
\hline Nome & NIS & Situoçâo & Periodo & [Valor do beneficicol] \\
\hline [João Carlos A. Souza] & [123.455.789-01] & [Faltou à escola mais que opermitido] & ] [JULHO/2015] & |Valor do beneficiol \\
\hline [João A. Souza] & [123.455.789.01] & [Não tomou as vacinas necessárias] & [10 semestre/2015] & [Valor do beneficiol \\
\hline [Joana Carla A. Souza & [ [123.455.789.01] & [Gestante náo fez o pré-natal] & [10 semestre/2015] & [Valor do beneficiol \\
\hline [Joбo Carlos A. Souzo] & {$[123.455 .789-01]$} & [Faltou d̀ escola mais que o permitido] & | [JULHO/2015] & [Valor do beneficicol] \\
\hline [Joôo Carlos A. Souzo] & [123.455.789-01] ] & [Faltou à escola mais que o permifido] & ] [JULHO/2015] & Valor do beneficiol \\
\hline [João Carlos A. Souza] & [123.455.789-01] & [Faltou à escola mais que o permifido] & 1] [JULHO/2015] & [Valor do beneficio] \\
\hline [Joáo Carlos A. Souza] & [123.455.789.01] & [Faltou à escola mais que o permitido] & ] [JULHO/2015] & Valor do beneficiclel \\
\hline [Jodo Carlos A. Souzo] & [123.455.789-01] & [Faltou da escola mais que o permitido] & ] [JULHO/2015] & [Valor do beneficiol \\
\hline [Jođ̃o Carlos A. Souzo] & [123.455.789-01] & [Foltou à escola mais que o permitido] & ] [JULHO/2015] & |Valor do beneficiol \\
\hline [João Carlos A. Souza] & [123.455.789.01] & [Fallou à escola mais que o permilido] & ] [JULHO/2015] & [Valor do beneficiol \\
\hline
\end{tabular}

Para não perder essa quantia, sua família precisa voltar a cumprir todos os compromissos do Programa Bolsa Família.

O Governo Federal quer te ajudar a cumprir todos esses compromissos. Para isso, procure o setor do Bolsa Familia ou o CRAS na sua cidade.

Se você acha que houve algum erro ou caso tenha alguma dúvida, ligue 08007072003. A ligação é de graça.

Lembre-se dos seus compromissos com o Programa Bolsa Família

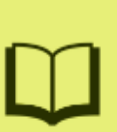
Crianças e
adolescentes de 6
a 17 anos devem frequentar a escola.

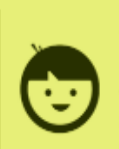
Crianças menores de 7 anos devem ser pesadas, medidas $e$ vacinadas conforme o calendário do Ministério da Saúde.

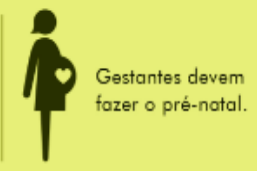

Ao gestor do Programa Bolsa Familia:

Motivo da correspondência: Descumprimento de condicionalidades

Caso a família informe erro no registro de descumprimento ou apresente uma justificativa, cadastre e avalie o recurso no Sistema de Condicionalidades (Sicon).

Se a familia apresentar indicios de vulnerabilidade ou risco social, comunique o setor de assistência social do seu município para avaliaçáo da necessidade de acompanhamento familiar com registro no Sicon.

Figura 5. Proposta de formato para a carta de advertência.

Fonte: Elaborado pelos autores.

É importante destacar aqui que o uso do viés de aversão à perda foi utilizado no sentido de enfatizar o valor, em reais, que pode ser perdido pela família caso ela permaneça em situação de descumprimento. A opção por deixar saliente o valor que estava sendo perdido se deu pelo alto valor relativo do benefício em relação à renda familiar. Espera-se que o imediatismo do ser humano, apontado por Thaler e Sunstein (2008), e o processo decisório de pessoas em situação de escassez possam produzir melhores resultados em termos de adesão (cf. Figuras 6 e 7, em destaque).

\section{Atençol Sua famlla pode PERDER IVALOR DO BENEFiOOI porque alguém sob sua responsabilidade nð̊o cumpriu os compromissos do Bolsa familia. Veja quem esteve nessa situaçäo irregular e qual o valor que a sua familia pode perder.}

Figura 6. Uso de frame de aversão à perda (1).

Fonte: Elaborado pelos autores. 
Para noo perder essa quantia, sua familia precisa voltar a cumprir todos os compromissos do Programa Bolsa Familia.

Figura 7. Uso de frame de aversão à perda (2).

Fonte: Elaborado pelos autores.

Procurando dirimir o caráter ameaçador que a carta pode vir a ter, foi inserido um texto abaixo da tabela que expõe os nomes das pessoas que estão em descumprimento (cf. Figura 8), ressaltando que o Governo Federal tem a intenção de ajudar as famílias a cumprirem os seus compromissos com o PBF.

\section{Governo Federal quer te ajudar a cumprir todos esses compromissos. Para isso, procure o setor do Bolsa Famflia ov o CRAS na sua cidade.}

Figura 8. Texto que objetiva dirimir o possível caráter ameaçador da carta.

Fonte: Elaborado pelos autores.

Veja-se que as mudanças propostas pelo uso de insights comportamentais em políticas públicas são, de fato, sutis, e tendem a causar efeitos justamente por trabalharem com a maneira como as pessoas percebem o ambiente em que se encontram.

\subsection{A proposta de avaliação de impacto para a intervenção}

Ao propor uma intervenção no Bolsa Família, também é necessário propor formas de avaliar o impacto, seja positivo, negativo ou nulo dessa intervenção. Avaliar os possíveis impactos de uma política pública é importantíssimo em tempos que exigem do gestor público um uso eficiente de recursos que são cada vez mais escassos (Gertler et al., 2015). Sunstein (2014) destaca a importância das análises de impacto para se ter uma ideia de custo/benefício de qualquer intervenção. Além disso, o autor acredita que cada vez mais os governos vão precisar de mais e melhores avaliações realizadas por meio de experimentos controlados.

A avaliação e monitoramento dos resultados também conferem legitimidade às políticas públicas, tanto interna, quanto externamente à própria administração. Internamente, isso se dá porque, em geral, os agentes públicos precisam argumentar e defender suas ideias perante autoridades superiores ou junto ao órgão responsável pela gestão dos recursos públicos. Externamente, ocorre porque é necessário algum tipo de transparência do governo em relação ao uso de recursos públicos, a fim de legitimar a atuação perante à população (Gertler et al., 2015).

Gertler et al. (2015) advogam que as avaliações prospectivas, pensadas no momento da elaboração da política pública, são mais propensas a produzirem melhores resultados. Para fundamentar esse posicionamento, o autor cita três argumentos: (i) o estabelecimento de uma coleta de dados pré-programa; (ii) uma projeção de resultados pretendidos antes da implementação do programa; e (iii) o estabelecimento de um grupo de controle e de tratamento antes da implementação do programa.

Gertler et al. (2015, p. 34) também ensina que a avaliação de uma política pública deve buscar uma relação de causa/efeito entre a política pública e os resultados por ela intencionados. Nesse sentido, afirma que a pergunta básica a se fazer quando se avalia uma política pública é: "qual é o impacto ou o efeito causal de um programa P sobre um resultado de interesse Y?" e que a resposta é dada pela fórmula:

$$
\alpha=(Y \mid \mathrm{P}=1)-(Y \mid \mathrm{P}=0)
$$

Nessa fórmula, $\alpha$ representa o impacto causal, $(Y \mid \mathrm{P}=1)$ representa o resultado de interesse $Y$ obtido com a presença do programa $\mathrm{P}$ e $(Y \mid \mathrm{P}=0)$ representa o resultado de interesse sem a presença do programa P (Gertler et al., 2015).

No caso da proposta de alteração nos textos das cartas que são enviadas aos beneficiários do PBF em situação de descumprimento de alguma condicionalidade do programa, a pergunta seria "qual é o impacto ou efeito das novas cartas no percentual de famílias que voltam a cumprir todas as condicionalidades do PBF?". Nessa situação, P seria o novo modelo de carta e Y o percentual de famílias que voltam à situação regular no programa após serem advertidas. Já o impacto causal $\alpha$ seria a diferença entre 0 
percentual de famílias que receberam o novo modelo de carta e que voltaram a situação regular no quesito das condicionalidades e o percentual das mesmas famílias que voltaram a situação regular, mas recebendo os modelos antigos.

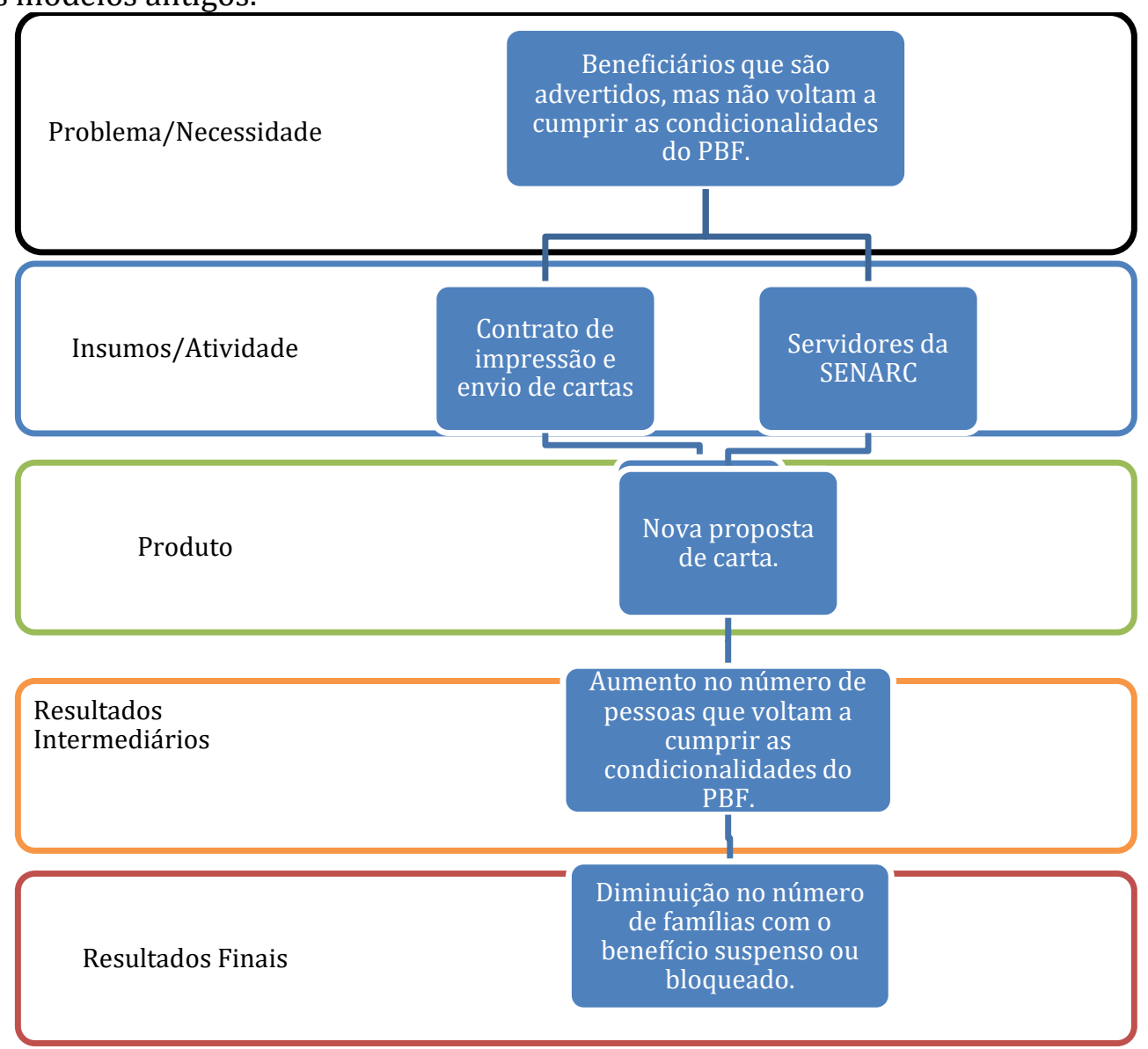

Figura 9. Teoria da mudança no novo modelo de cartas de advertência. Fonte: Elaborada pelos autores.

Nesse caso, pode-se perceber a impossibilidade de se aferir o impacto causal da forma que foi expressa, pois não é possível obter-se um resultado para os mesmos sujeitos (isto é, as mesmas famílias) sendo alvo e não sendo alvo das propostas de intervenção. Nesse sentido, Gertler et al. (2015) apresentam o conceito de contrafactual, que é uma estimativa de como seria o efeito Y sem presença do programa $\mathrm{P}(\mathrm{P}=0)$. No caso da proposta desse trabalho, o contrafactual seria uma estimativa do que teria acontecido com essas famílias, caso tivessem recebido o modelo atual das cartas.

Ao se elaborar uma proposta de avaliação para qualquer política pública, faz-se necessário a construção de uma Teoria da Mudança que descreva com clareza o problema (ou necessidade) a ser enfrentado, os insumos (ou atividades) que serão utilizados, o produto, os resultados imediatos e o resultado a longo prazo (Gertler et al., 2015). Nesse sentido, a Figura 9, apresentada acima, representa a teoria da mudança da nova redação das cartas de advertência enviadas aos beneficiários em situação de descumprimento de condicionalidades do PBF.

\subsection{Proposta de avaliação de impacto para o novo modelo de carta de advertência}

No caso de se avaliar o novo modelo de cartas advertência, é necessário observar que o modelo atual de advertência tem uma taxa de sucesso de aproximadamente 63,2\%, uma vez que das 221.386 famílias que são advertidas, apenas 81.448 passam para o estágio de bloqueio do benefício. No entanto, não se sabe exatamente o porquê dessas famílias voltarem a cumprir as condicionalidades do PBF, uma vez que elas são advertidas de duas formas: carta e mensagem no extrato bancário emitido pela Caixa.

Nesses termos, propõe-se que das 221.386 famílias elegíveis ao envio do novo formato de carta de advertência, seja sorteada uma quantidade definida por cálculos estatísticos para a formação da amostra da avaliação de impacto. Feito isso, seria realizado um novo sorteio para a formação de três 
grupos de tratamento e um grupo de controle. 0 grupo de controle será advertido da mesma forma que as famílias são advertidas atualmente: modelo atual de carta e extrato bancário emitido pela Caixa. Os três grupos ficam denominados de grupos de tratamento A, B e C. $\mathrm{O}$ tratamento A corresponde a ser advertido apenas com a carta do modelo atual. Já o grupo de tratamento B corresponde a ser advertido apenas pelo extrato bancário emitido pela Caixa. Finalmente, o grupo de tratamento C corresponde a ser advertido apenas pela carta no formato proposto neste trabalho (cf. figura 10).

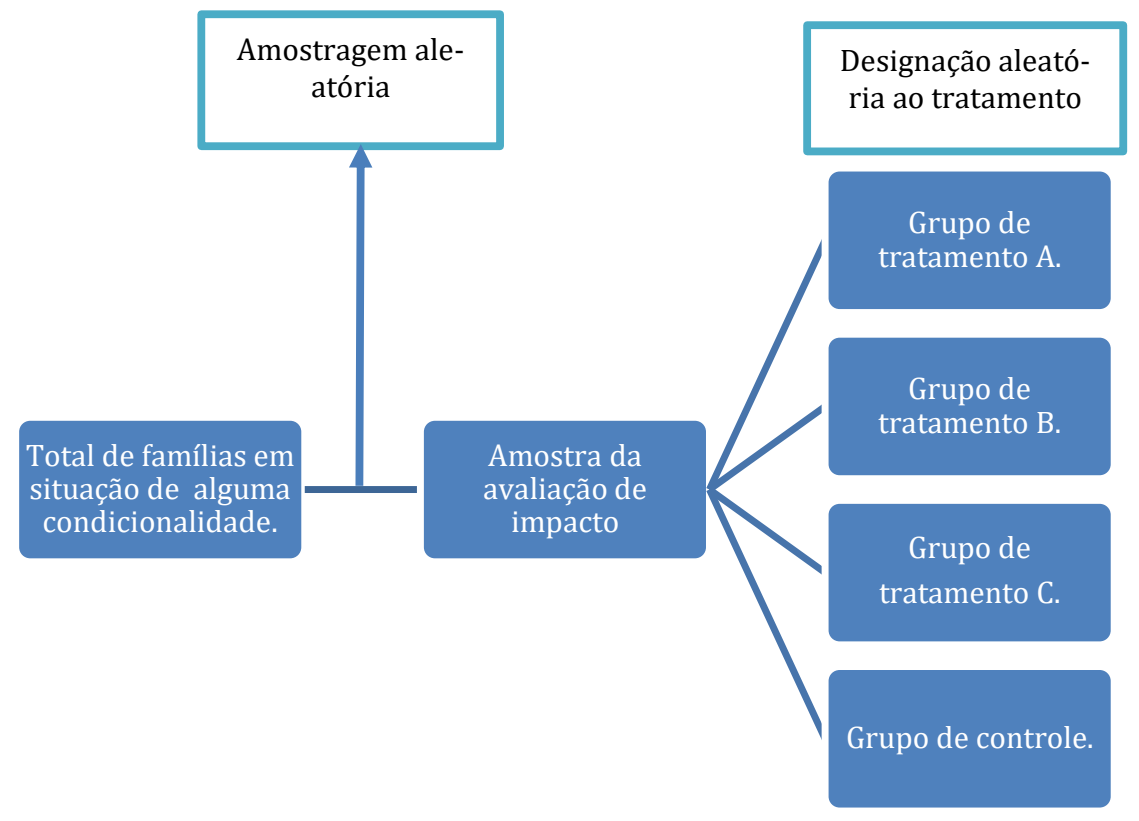

Figura 10. Proposta de avaliação do novo formato de advertência.

Fonte: elaborada pelos autores.

Ao implementar essa proposta de avaliação de impacto, o Ministério da Cidadania estará, pela primeira vez, desde o lançamento do PBF, aferindo a melhor forma de se comunicar com o beneficiário do Programa. 0 resultado dessa avaliação pode impactar nos custos do programa. Por exemplo, caso o resultado demonstre que a comunicação feita apenas pelo extrato bancário tem o mesmo efeito da comunicação feita por carta e extrato, poderia ser poupado o recurso gasto com a postagem das cartas.

\section{Considerações finais}

0 presente artigo se propôs a apresentar uma proposta de intervenção no Programa Bolsa Família, com a respectiva proposta de avaliação de impacto. Foi feita uma breve análise acerca do PBF, destacando a importância das condicionalidades como um dos vértices da política pública. Em seguida, foram analisados alguns insights comportamentais específicos que serviram de fundamentação teórica para uma proposta de intervenção no PBF apresentada neste trabalho.

Foi também apresentado um novo formato para as cartas de advertência que são enviadas para famílias em situação de descumprimento de determinada condicionalidade do PBF. Foram propostas duas alterações: a primeira na cor do papel, optando-se pela cor amarela para chamar mais a atenção do beneficiário para a carta. A segunda foi na linguagem utilizada na carta, com a inclusão do valor em reais que a família poderia perder, caso não cumprisse com as condicionalidades do programa, explorando-se o viés de aversão à perda das pessoas.

Além da ferramenta, foi proposta a respectiva avaliação de impacto que poderá comprovar ou não a eficácia da referida intervenção. A avaliação de impacto é de suma importância para que, antes de uma possível implementação em larga escala, se tenha uma clara ideia da relação de custo/benefício dessa proposta.

Sunstein (2014) destaca a importância das análises de impacto para se ter uma ideia de custo/benefício de qualquer intervenção. Portanto, partindo das revisões bibliográficas apresentadas e das propostas de intervenção no PBF com as respectivas propostas de avaliação de impacto, espera-se que o 
novo modelo de carta de advertência possa gerar uma diminuição no quantitativo de famílias que passam do estágio de advertência para o de bloqueio do benefício e, por consequência, um maior número de famílias que cumprem as condicionalidades do programa, ou seja, que as famílias mantenham suas crianças na escola, com o cartão de vacinação em dia e que as gestantes estejam com os exames prénatais realizados.

É importante destacar algumas das limitações da proposta que é objeto deste artigo. Uma delas concerne à sua avaliação de impacto, uma vez que se propõe uma metodologia experimental. Embora o uso de métodos experimentais para a avaliação de políticas de transferência de renda já seja uma realidade em países como o México, o Brasil ainda não adotou de forma massificada essa estratégia de avaliação. Dado que o uso do método experimental implicaria a divisão dos beneficiários em grupos de tratamento e de controle, essa abordagem poderia levantar questionamentos de natureza ética. Contudo, os métodos experimentais ainda representam o "padrão ouro" da inferência causal. Nesse sentido, a avaliação do novo modelo de cartas de advertência demandaria uma inovação metodológica desafiadora nos estudos governamentais sobre o PBF.

Como implicações práticas, espera-se que a intervenção aqui proposta possa atenuar o número de famílias em descumprimento de condicionalidades e, consequentemente, reduzir o número de bloqueios, suspensões e cancelamentos de benefícios do PBF. Em face do atual contexto de ajuste fiscal que ainda afeta a dinâmica da economia brasileira, é necessário pensar em estratégias que assegurem a cobertura do PBF às famílias necessitadas. As evidências empíricas da literatura de EC e as experiências internacionais sugerem que as políticas públicas podem ser aprimoradas a partir de intervenções pequenas e de baixo custo. Dada a importância do PBF no combate à pobreza no Brasil, espera-se que essa proposta encontre respaldo entre gestores públicos e pesquisadores interessados no aprimoramento de políticas de transferência de renda condicionada.

\section{Referências}

Agatte, J. P., Antunes, M. M. (2014). Condicionalidade de Educação do Programa Bolsa Família: Concepção e Organização de Acompanhamento. Cadernos de Estudos - Desenvolvimento Social em Debate, 18, 36-49.

Banco Mundial. (2015). Relatório sobre o desenvolvimento mundial 2015: mente, sociedade e comportamento. Washington, DC: Banco Mundial.

BIT - Behavioural Insights Team (2012). Applying behavioural insights to reduce fraud, error and debt. London: Behavioural Insights Team.

Briscese, G. \& Tan, C. (2018). Applying Behavioural insights to labour market. London, Behavioural Insights Team.

Cambraia, A. (2012). Efeitos do Programa Bolsa Família sobre a desigualdade e a extrema pobreza: análise e evidências a partir do Censo Demográfico 2010. Revista Brasileira de Monitoramento e Avaliação, 3, 76-95.

Camerer, C. F. (2000). Prospect theory in the wild: Evidence from the field. In Kahneman, D. and Tversky, A. (Eds.), Choices, Values, and Frames. New York: Russel Sage Foundation, Cambridge University Press. Campos Filho, A. C. C. \& Paiva, L. H. (2018). Behavioural insights in poverty reduction policies. International Policy Centre for Inclusive Growth, 60. Recuperado de: http://www.ipcundp.org/pub/eng/PRB60_Behavioural_insights_in_poverty_reduction_policies.pdf

Cezar, L. C. (2018). Reflexões sobre a comunicação em políticas públicas: proposta de um modelo de avaliação da comunicação governamental. Revista de Administração Pública, 1(52), 52-70.

Cotta, T. C. \& Paiva, L. H. (2010). O Programa Bolsa Família e a proteção Social no Brasil. In Bolsa Família 2003 - 2010: avanços e desafios, 1, 57-101.

DellaVigna, S. (2009). Psychology and economics: Evidence from the field. Journal of Economic Literature, 2(47), 315-372.

Gächter, S., Orzen, H., Renner, E., \& Starmer, C. (2009). Are experimental economists prone to framing effects? A natural field experiment. Journal of Economic Behavior \& Organization, 3(70), 443-446.

Gertler, P. J., Martínez, S., Premand, P., Rawlings, L. B. \& Vermeersch, C. M. J. (2015). Avaliação de Impacto na Prática, (2 ${ }^{\mathrm{a}}$. ed.). Washington, DC: Banco Interamericano de Desenvolvimento e Banco Mundial.

Januzzi, P. D. M., \& Pinto, A. R. (2010). Bolsa Família e seus impactos nas condições de vida da população brasileira: uma síntese dos principais achados da pesquisa de avaliação do impacto do Bolsa Família 
II. In Bolsa Família 2003 - 2010: avanços e desafios, 1, 157-178.

Kahneman, D. (2012). Rápido e devagar: duas formas de pensar. Objetiva.

Kahneman, D. \& Tversky, A. (1979). Prospect theory: An analysis of decision under risk. Econometrica, 2 (47), 263-291.

Lentz, E.C., Barrett, C.B. \& Hoddinott, J. (2005). Food Aid and Dependency: Implications for Emergency Food Security Assessments. World Food Programme SENAC project.

Lindert K., Linder A., Hobbsa J. \& Briére, B. (2007). The nuts and bolts of Brazil's Bolsa Família Program: implementing conditional cash transfers in a descentralized context. Discussion Paper, 709. Washington, DC: World Bank.

Maurício, M.F. \& Cardoso, G. (2019). Desempenho e Resultados: A lógica da Gestão Descentralizada do Programa Bolsa Família e do Cadastro Único para Programas Sociais do Governo Federal. In Silva, T. F. (Org.). Bolsa Família 15 Anos (2003-2018), 79-107. Brasília: ENAP.

Meneguin, F. B., \& Ávila, F. (2015). A economia comportamental aplicada a políticas públicas. In Ávila, F. \& Bianchi, A. M. Guia de Economia Comportamental e Experimental (Laura Teixeira Motta, Trad.). economiacomportamental.org, 212-215.

Mullainathan, S., \& Shafir, E. (2016). Escasez: ¿ Por qué tener muy poco significa tanto? Ciudad de México: Fondo de Cultura Económica.

OCDE. (2017). Behavioural insights and public policy: Lessons from around the world. OCDE.

Paiva, L. H., Falcão, T., \& Bartholo, L. (2013). Do Bolsa Família ao Brasil Sem Miséria: um resumo do percurso brasileiro recente na busca da superação da pobreza extrema. International Policy Centre for Inclusive Growth, 228. Recuperado de: https://ipcig.org/pub/port/IPCOnePager228.pdf

Samson, A. (2015). The behavioral economics guide. (with an introduction by Dan Ariely). [Webite] Recuperado de: http://www.behavioraleconomics.com.

Simões, P. \& Soares, R. B. (2012). Efeitos do Programa Bolsa Família na fecundidade das beneficiárias. Revista Brasileira de Economia 66(4).

Soares, S. \& Sátyro, N. (2009). O Programa Bolsa Família: desenho institucional, impactos e possibilidades futuras. Texto para Discussão, 1424. Brasília: IPEA.

Starmer, C. (2015). Entendendo preferências: o que podemos aprender com a economia comportamental? In Ávila, F. \& Bianchi, A. M. (orgs.). Guia de economia comportamental e experimental (Laura Teixeira Motta, Trad.). Economia Comportamental, 61-76.

Sunstein, C. (2014). Why nudge? The politics of libertarian paternalism. New Haven: Yale University Press.

Thaler, R. \& Sunstein, C. (2008). Nudge: improving decisions about health, wealth, and happiness. New Haven: Yale University Press.

Ximenes, D. \& Agatte, J. (2011). A gestão das condicionalidades do Programa Bolsa Família: uma experiência intersetorial e federativa. Inclusão Social, 1(5), 11-19.

Zucco, C., Luna, J. P., \& Baykal, O. G. (2020). Do Conditionalities Increase Support for Government Transfers? The Journal of Development Studies, 3(56), 527-544. 